\title{
Antibacterial Effect of Endodontic Disinfections on Enterococcus Faecalis in Dental Root Canals-An In-Vitro Model Study
}

\author{
Stefan Kranz *D, André Guellmar, Franziska Braeutigam, Silke Tonndorf-Martini, Markus Heyder, Markus Reise \\ and Bernd Sigusch
}

check for

updates

Citation: Kranz, S.; Guellmar, A.; Braeutigam, F.; Tonndorf-Martini, S.; Heyder, M.; Reise, M.; Sigusch, B. Antibacterial Effect of Endodontic Disinfections on Enterococcus Faecalis in Dental Root Canals-An In-Vitro Model Study. Materials 2021, 14, 2427. https://doi.org/10.3390/ ma14092427

Academic Editor: Tonino Traini

Received: 21 March 2021

Accepted: 1 May 2021

Published: 7 May 2021

Publisher's Note: MDPI stays neutral with regard to jurisdictional claims in published maps and institutional affiliations.

Copyright: (C) 2021 by the authors Licensee MDPI, Basel, Switzerland. This article is an open access article distributed under the terms and conditions of the Creative Commons Attribution (CC BY) license (https:/ / creativecommons.org/licenses/by/ $4.0 /)$.
Department of Conservative Dentistry and Periodontology, Jena University Hospital, Friedrich-Schiller-University, An der Alten Post 4, 07743 Jena, Germany; andre.guellmar@med.uni-jena.de (A.G.); Franziska_braeutigam@web.de (F.B.); Silke.Tonndorf-Martini@med.uni-jena.de (S.T.-M.); Markus.Heyder@med.uni-jena.de (M.H.); Markus.Reise@med.uni-jena.de (M.R.); Bernd.W.Sigusch@med.uni-jena.de (B.S.)

* Correspondence: Stefan.Kranz@med.uni-jena.de

\begin{abstract}
Enterococcus faecalis (E. faecalis) is rather unsusceptible to many root canal disinfections which often cause a therapeutic problem. Therefore, the present in vitro study observed the efficiency of different endodontic antiseptics in their capability to suppress E. faecalis, especially inside dentinal tubules. Prior to any testing, root canals of extracted third human molars were inoculated with E. faecalis for $48 \mathrm{~h}$. Antiseptic dressings with chloramine-T or calcium hydroxide $(\mathrm{CaOH})$ for $24 \mathrm{~h}$ or irrigations with $1.3 \%$ sodium hypochlorite $(\mathrm{NaOCl})$ were applied with $n=10$ in each group. As control irrigation with normal saline was used. All treated canals were manually enlarged from size ISO 50 to 110 and the ablated dentin debris was subjected to microbial culture analysis. Bacterial colonization of the dentinal tubules up to $300 \mu \mathrm{m}$ was verified by scanning electron microscopy and histological sample preparation. Application of crystalline chloramine-T caused total bacterial suppression inside the dentinal tubules. Dressings with $\mathrm{CaOH}$ showed only minor effects. Irrigation with $\mathrm{NaOCl}$ caused total eradication of bacteria adhering to the root canal walls, but also failed to completely suppress E. faecalis inside the dentinal tubules. The study showed that chloramine-T is of strong antiseptic activity and also efficient in suppressing E. faecalis inside dentinal tubules.
\end{abstract}

Keywords: chloramine-T; Enterococcus faecalis; temporary dressing; calcium hydroxide; sodium hypochlorite; intracanal disinfection; root canal treatment; endodontic treatment

\section{Introduction}

Chemo-mechanical root canal preparation involves the removal of pathogens by mechanical shaping of the root canal walls accompanied by an alternating irrigation with disinfection fluids. The treatment of infected dental root canals by high quality disinfection is crucial to ensure healing of the apical region and long-term success of an endodontic therapy. In this regard, pathogens that have survived inside dentinal tubules or in inaccessible areas of the root canal system might cause re-infection and treatment failure [1,2].

In those cases, it was shown that in post-treatment endodontic flare-ups besides Streptococci, Lactobacilli, Actinomyces and fungi, the Gram-positive bacterial species Enterococcus faecalis (E. faecalis) is often detected $[3,4]$. Investigations have shown that in cases of secondary root canal infections the prevalence of E. faecalis can reach values up to $70 \%$ [5-8].

E. faecalis is also known to be rather unsusceptible towards many disinfectants commonly applied during antiseptic root canal treatment which include chlorhexidine $[9,10]$, sodium hypochlorite [11,12] and calcium hydroxide [13,14]. Even exposure to clindamycin, 
tetracycline, erythromycin or treatment with Lugol's iodine solution as well as mineral trioxide aggregate was not efficient in suppressing the species completely [15-17].

Unlike others, E. faecalis is also able to penetrate far into the dentinal tubules which ensures protection from antiseptic measures, too [2].

In order to overcome the lack of inefficient intracanal disinfection, new chemical compounds and methods are constantly under investigation for their suitability in endodontic antiseptic treatment [18-23].

Surprisingly, the already known disinfectant N-chloro tosylamide sodium salt (chloramine-T) shows promising characteristics [24]. Chloramine-T is of high chlorination and oxidation power and proofs sufficient antimicrobial behavior towards a wide variety of microorganisms including bacteria, fungi, yeasts and also human pathogenic viruses such as coxsackie, parainfluenza, adeno-, polio- and corona-viruses [25-27].

In contrast to sodium hypochlorite $(\mathrm{NaOCl})$ which is still considered the "gold standard" in chemo-mechanical root canal preparation, chloramine- $\mathrm{T}$ is also of less cytotoxicity $[24,27,28]$.

Although chloramine-T is a well-known disinfectant, studies investigating the bactericidal effect on endodontic pathogens are still rather rare. Especially for pathogens such as $E$. faecalis which are able to colonize dentinal tubules, application of chloramine-T by means of a temporary dressing might be of potential interest.

Therefore, the present in vitro study was aimed on investigating the antibacterial effect of chloramine- $\mathrm{T}, \mathrm{CaOH}$ and $\mathrm{NaOCl}$ in their capability to suppress E. faecalis inside the dental root canal system and especially inside dentinal tubules.

\section{Materials and Methods}

\subsection{Cultivation of Enterococcus Faecalis}

In the present in vitro study the Gram-positive bacterial species Enterococcus faecalis (ATCC 29212) was used. The strain was grown under anaerobic standard conditions $\left(80 \% \mathrm{~N}_{2}, 10 \% \mathrm{CO}_{2}\right.$, and $\left.10 \% \mathrm{H}_{2}\right)$ in $10 \mathrm{~mL}$ Schaedler fluid media (Oxoid Ltd., Hampshire, UK) for $3 \mathrm{~h}$. Subsequently, bacteria were harvested by centrifugation (4000 rpm, $8 \mathrm{~min}$ ) and washed twice with PBS. For inoculation, bacterial solutions were arranged by re-suspending the bacterial pellet in Schaedler fluid media (OD546nm of 0.5 which corresponds to $10^{8} \mathrm{CFU} / \mathrm{mL}$ ).

\subsection{Preparation of the Dental Root Canals}

A total of 50 extracted non-decayed human wisdom teeth with round and straight roots were collected and stored in normal saline at $4{ }^{\circ} \mathrm{C}$ until use. The study was approved by the Ethics Committee of the Faculty of Medicine, University Hospital Jena, Germany (\#2019-1401-Material). Informed consent of each patient was given.

Prior to any treatment, soft tissue remands were removed from the external root surfaces with curettes (Hu-Friedy, Frankfurt am Main, Germany). Subsequently, the crowns were removed using a water-cooled cut-off wheel (Horico Dental, Berlin Germany) to receive final root lengths of $10 \mathrm{~mm}$. The pulp tissue was removed and the root canals were manually enlarged with files (Densply Detrey GmbH, Konstanz, Germany) up to size ISO 50. For irrigation normal saline was used. To ensure a leak-proof outer insolation, the root surfaces were coated with glass ionomer cement (Ketac Bond, 3M ESPE, Neuss, Germany). For more convenient handling, the prepared root specimens were embedded in Flexitime impression putty material (Heraeus Kulzer GmbH, Hanau, Germany). In Figure 1 the enlargement of the main root canal with endodontic files and irrigation with normal saline is shown.

\subsection{Inoculation of the Root Canals with E. faecalis}

Prior to inoculation, all canals were irrigated with $2 \mathrm{~mL}$ Calcinase (lege artis Pharma $\mathrm{GmbH} \& \mathrm{Co} \mathrm{KG}$, Dettenhausen, Germany) for $180 \mathrm{~s}$ and afterwards rinsed with $3 \mathrm{~mL}$ 
distilled water each. Subsequently, all specimens were autoclaved in a moist chamber for 20 min at $121^{\circ} \mathrm{C}$.

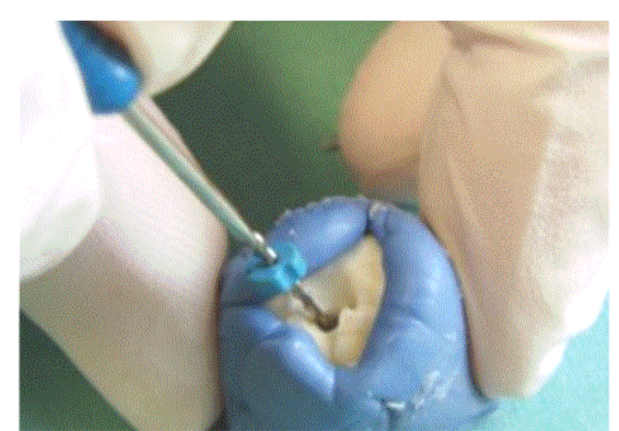

(a)

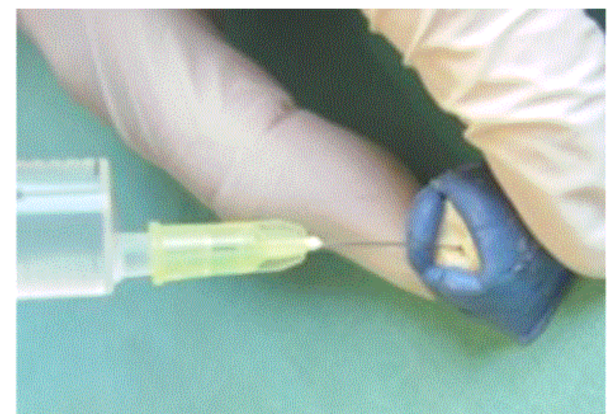

(b)

Figure 1. The picture shows root specimens embedded in putty material: (a) enlargement of the main root canal with endodontic files; (b) irrigation of the shaped canal with normal saline.

After sterilization, all root canals were inoculated with $100 \mu \mathrm{L}$ of the E. faecalis suspension $\left(\mathrm{OD}_{546 \mathrm{~nm}}\right.$ of 0.5$)$ for $48 \mathrm{~h}$ under anaerobic standard conditions $\left(80 \% \mathrm{~N}_{2}, 10 \% \mathrm{CO}_{2}\right.$, and $10 \% \mathrm{H}_{2}$ ). To avoid drying of the samples, all specimens were moistened with Schaedler fluid media after $24 \mathrm{~h}$ of incubation.

\subsection{Microscopic Evaluation of the Infected Root Specimens}

After $48 \mathrm{~h}$ bacterial colonization of the dentinal tubules was observed by scanning electron microscopy. Therefore, the infected specimens were prepared as described at Kneist et al. [29]. In brief, after infection with E. faecalis the roots were fractured and fixed with $2.5 \%$ glutaraldehyde/cacodylate buffer for $24 \mathrm{~h}$, washed three times in cacodylate buffer and subsequently dehydrated for 30-60 min by sequential washes in 30\% to 100\% graded ethanol. After critical-point drying, the specimens were sputtered with gold and observed using a scanning electron microscope (LEO 1450VP, Zeiss, Oberkochen, Germany) at 20-20,000× magnification.

In addition, remands of the fractured and fixed specimens were subjected to histological evaluation, too. Therefore, the fragments were additionally decalcified in $10 \%$ EDTA for 12 weeks at $37^{\circ} \mathrm{C}$, embedded into paraffin and cut by a microtome. Subsequently, all samples were stained according to Brown and Brenn. Evaluation was performed using brightfield microscopy at $40 \times$ magnification.

\subsection{Root Canal Disinfection with Chloramine-T}

All infected specimens $(n=50)$ were assigned into 5 randomized groups each with $\mathrm{n}=10$ samples. In test group 1 (chloramine-T CP), root canals were completely packed each with $7 \mathrm{mg}$ of crystalline chloramine-T (concentration 99\%) (Merck Chemicals $\mathrm{GmbH}$, Darmstadt, Germany). In test group 2 (chloramine-T PP), sterile paper points were moistened with normal saline and subsequently dip coated with an average of $1.3 \mathrm{mg}$ crystalline chloramine-T. Afterwards, the coated paper points were inserted into the infected root canals. Subsequently, all specimens were incubated in a moistened chamber for $24 \mathrm{~h}$ under anaerobic standard conditions $\left(80 \% \mathrm{~N}_{2}, 10 \% \mathrm{CO}_{2}\right.$, and $\left.10 \% \mathrm{H}_{2}\right)$. Additionally, all canals were closed by a top seal with Flexitime impression putty material.

In control group 1 calcium hydroxide paste $\left(\right.$ Calcicur $^{\circledR}$, VOCO GmbH, Cuxhaven, Germany) was applied as intracanal dressing for $24 \mathrm{~h}$. To simulate a saliva-proof seal, all canal orifices were closed with Flexitime impression putty material, too.

In test group 3 the root canals were irrigated for $20 \mathrm{~s}$ with $5 \mathrm{~mL}$ of a $1.3 \%$ sodium hypochlorite solution (Hedinger $\mathrm{GmbH}$, Stuttgart, Germany). In control group 2 normal saline $(5 \mathrm{~mL})$ was used for irrigation. 


\subsection{Microbial Analysis}

The applied methodology was adopted from Ossmann et al. [20]. In brief, after inoculation with E. faecalis for $48 \mathrm{~h}$, the samples were dried twice for $10 \mathrm{~s}$ each with ISO 50 paper points (DentsplyDeTrey, Konstanz, Germany). The used paper points (ISO 50) served as initial colonization control (baseline value-P0) and were traversed to a reaction vessel filled with $1 \mathrm{~mL}$ of physiological $\mathrm{NaCl}$ solution. After vortexing, dilution series down to $10^{-6}$ were arranged and aliquots $(100 \mu \mathrm{L})$ were plated onto sterile Schaedler agar. All plates were cultivated for $24 \mathrm{~h}$ under anaerobic standard conditions $\left(80 \% \mathrm{~N}_{2}, 10 \% \mathrm{CO}_{2}\right.$, and $\left.10 \% \mathrm{H}_{2}\right)$ and colony-forming unites $(\mathrm{CFU} / \mathrm{mL}$ ) were determined.

After treatment with the respective disinfectant another swap (P50) was taken from the canal wall by inserting two consecutive sterile paper points that were analyzed in the same way as already described.

Subsequently, all canals were manually enlarged with endodontic hand-held files (ANTAEoS CC+, VDW GmbH, Munich, Germany) from size ISO 60 to size ISO 110 (P60 to P110). Each file was turned 10 times by three-quarter rotations. The abraded dentin debris of each shaping step was collected and transferred together with the used file to a reaction vessel filled with $1 \mathrm{~mL}$ of normal saline. The remaining dentin debris was taken from the root canal with another paper point and also transferred to the same reaction vessel. Shaping and collecting of the dentin debris was carried out twice for each ISO size.

Preparation from one to the other ISO size resulted in reduction of the dentin wall by app. $50 \mu \mathrm{m}$. Before proceeding with the shaping process, any residual dentin debris was removed from the root canals by rinsing each canal with $3 \mathrm{~mL}$ of normal saline. The rinsing fluid was discharged. Subsequently, the pooled samples were vortexed, dilution series down to $10^{-6}$ were arranged and aliquots $(100 \mu \mathrm{L})$ were plated onto sterile Schaedler agar (Schaedler Anaerobic Agar, Oxoid Ltd., Hampshire, UK) supplemented with 6\% sheep blood and $0.1 \%$ vitamin K (Konakion MM 10 mg, Roche Pharma AG, Basel, Switzerland). Afterwards, all plates were cultivated anaerobically for $48 \mathrm{~h}$ and $\mathrm{CFU} / \mathrm{mL}$ were determined. The experimental setup is shown in Figure 2, too.

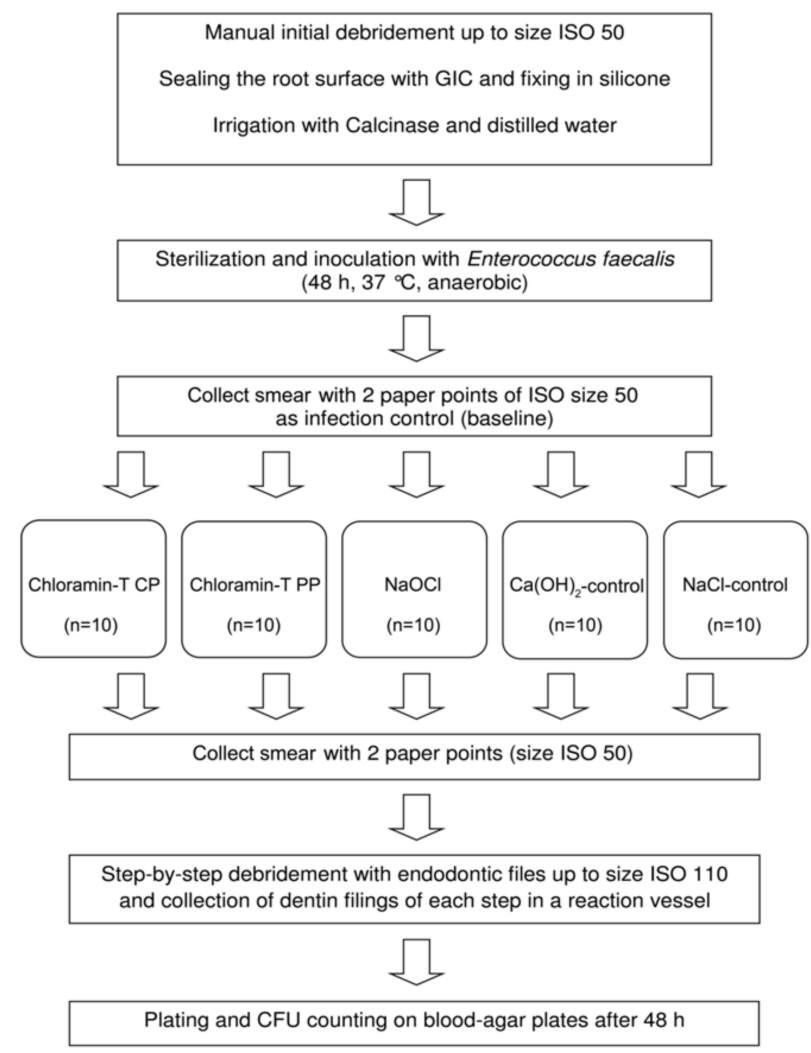

Figure 2. Flow-chart of the experimental setup. GIC-glass ionomere cement. 


\subsection{Data Analysis}

Statistical analysis was carried out using SPSS 20.0 PC software (SPSS, Inc., Dallas TX, USA). Significant differences between the groups were determined by applying the students' $t$-test. The level of statistical significance was $p<0.05$. Error corrections according to Bonferroni were additionally applied.

\section{Results}

The present in vitro study investigated the antibacterial effect of temporary dressings with chloramine-T and calcium hydroxide as well as irrigations with $1.3 \%$ sodium hypochloride on E. faecalis inside infected root canals. Chloramine-T was applied to the infected samples by either complete packing of the main root canal with solid chloramine-T crystals (Chloramine-T CP) or by moistened and dip-coated paper points (chloramine-T PP). As control irrigation with normal saline was used.

Prior to any antibacterial testing, colonization of the root canal system by E. faecalis was evaluated by microscopic examination. In Figure 3a-c scanning electron microscopic images (SEM) of infected root dentin samples are shown. It can be observed that $E$. faecalis invaded the dentinal tubules up to distances of at least $300 \mu \mathrm{m}$. A magnified image of lined up bacterial cells inside a dentinal tubule is shown in Figure 3c.

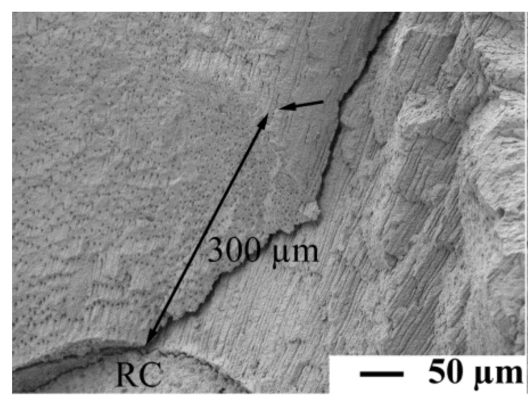

(a)

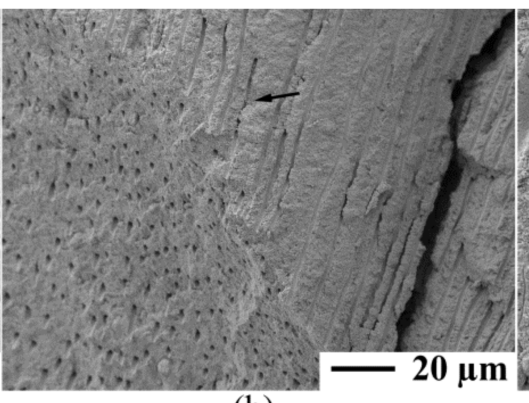

(b)

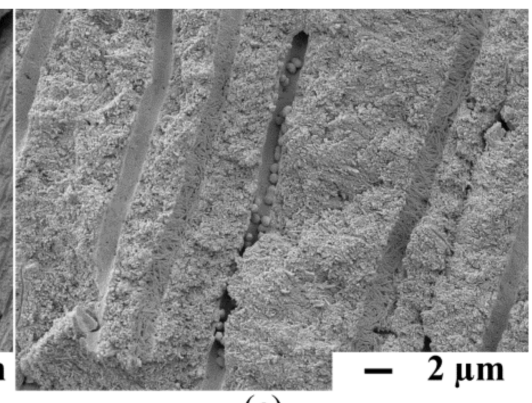

(c)

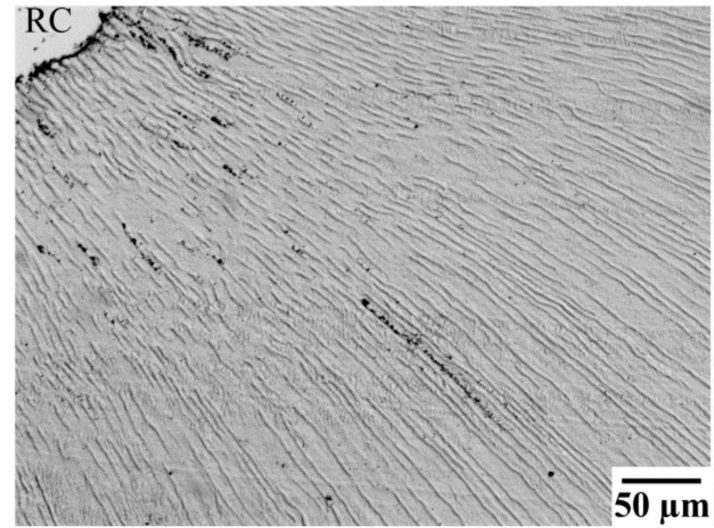

(d)

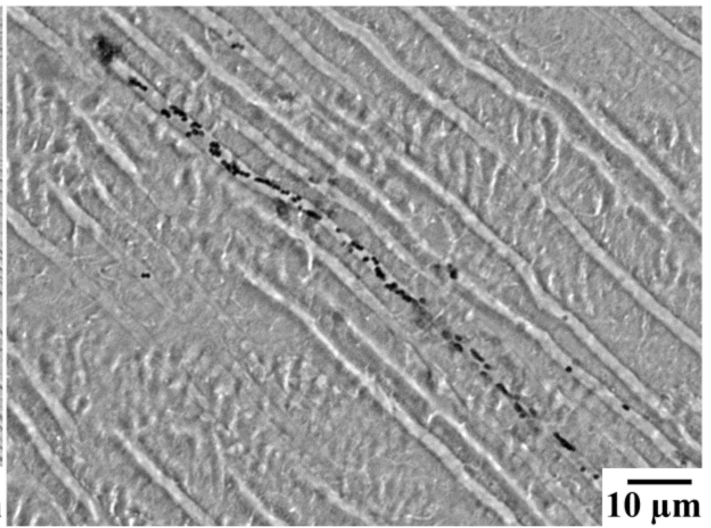

(e)

Figure 3. Scanning electron microscopic images $(\mathbf{a}-\mathbf{c})$ and histological sections $(\mathbf{d}, \mathbf{e})$ of root dentin samples showing bacteria that have invaded the dentinal tubules: $(\mathbf{a}-\mathbf{c})$ Series of magnified dentinal tubules. Bacteria inside a dentinal tubule are marked by a black arrow. The main root canal is labeled with RC; $(\mathbf{d}, \mathbf{e})$ Histological section and magnification of fixed bacterial cells inside dentinal tubules.

Within 48 h of inoculation E. faecalis was also able to form biofilms at the walls of the main root canals. In Figure $3 \mathrm{~d}$ bacterial cells adhering to the root canal wall and also cells that have invaded the dentinal tubules are shown. A detailed image of bacterial cells inside a dentinal tubule can also be viewed in Figure 3 e.

In order to evaluate the efficiency of each antimicrobial measure, the main root canal was enlarged stepwise from ISO 50 to ISO 110 and the abraded dentin debris was subjected to microbial culture analysis. Prior to any antimicrobial testing an average of 
$1.58 \times 10^{7} \mathrm{CFU} / \mathrm{mL}$ (P0 value-baseline) cells was estimated that adhered to the main root canal wall. In accordance to the microscopic evaluation, microbial culture analysis confirmed colonization of the dentinal tubules by E. faecalis up to distances of $300 \mu \mathrm{m}$, too (Figure 4, $\mathrm{NaCl}$ control, dashed line).

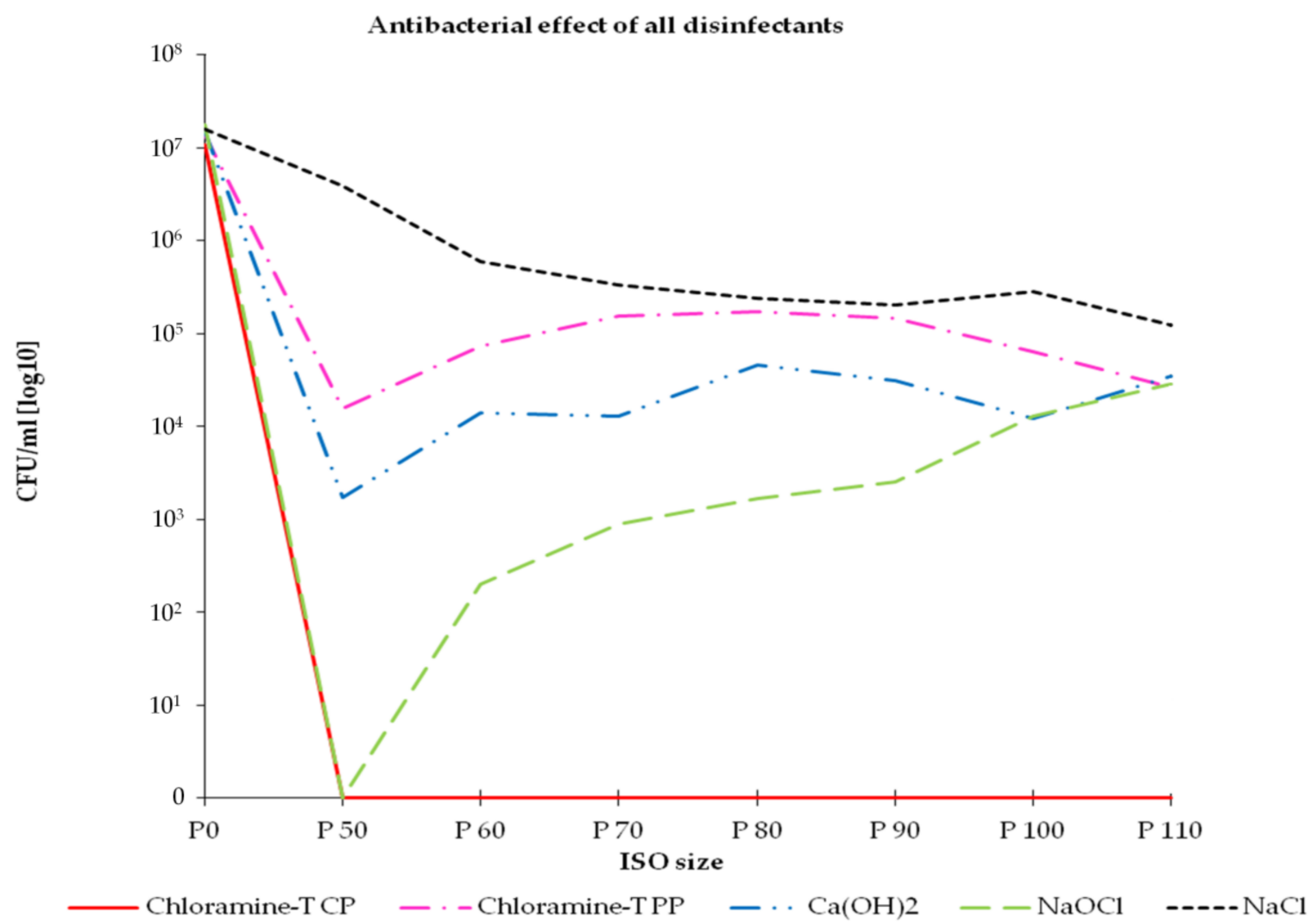

Figure 4. Antibacterial effect of all disinfectants that were applied. All root canals were manually enlarged from file size ISO 50 (P50) to size ISO 110 (P110). The collected dentin debris was subjected to microbial culture analysis. Microbial load of each ISO size is shown in CFU $/ \mathrm{mL}$. The baseline value (bacterial load of the main root canal before any antimicrobial measure) is termed P0. Additional graphical illustrations regarding the antimicrobial effect are attached as supplementary material.

Among all disinfectants tested, complete filling of the main root canal with crystalline chloramine-T (chloramine-T CP) for $24 \mathrm{~h}$ was most efficient in suppressing E. faecalis. As shown in Figure 3 complete filling of the main root canal with chloramine-T resulted in total suppression of the species. Culture analysis of the collected dentin debris confirmed complete suppression of E. faecalis up to file size ISO 110, which corresponds with a distance of penetration into the dentinal tubules by up to $300 \mu \mathrm{m}$.

In comparison, when chloramine-T was applied by moistened and dip-coated paper points (chloramine- $\mathrm{T} \mathrm{PP}$-test group 2) only bacteria that adhered to the walls of the main root canal were affected (ISO size 50). Microbial culture analysis estimated a reduction in $\mathrm{CFU} / \mathrm{mL}$ by 3 log-counts when compared to the P0 value. Bacteria that have invaded the dentinal tubules remained unaffected by this kind of disinfection measure. Vital cells could be recovered from the collected dentin debris in high numbers up to file size ISO 110.

In the following section results from the test and control groups are compared. There was no significant difference in the results obtained for the chloramine-T PP group when compared to the $\mathrm{CaOH}$ control. It was found that application of $\mathrm{CaOH}$ for $24 \mathrm{~h}$ resulted in a decrease by 3.9 log-counts of cells that colonized the canal walls directly, which was significantly not different from the results obtained for the chloramine-T PP group $(p=0.065)$. Further mechanical instrumentation of the main root canal up to file size ISO 110 did not reveal any significant change in the number of bacteria recovered when chloramine-PP was compared to the suppressive behavior of the $\mathrm{CaOH}$ control. 
Treatment with $\mathrm{CaOH}$ resulted in significant bacterial reduction inside the dentinal tubules which ranged in between 3.0 (ISO 60) and 2.6 (ISO 110) log counts when compared to the $\mathrm{P} 0$ value. Compared to chloramine- $\mathrm{CP}$, temporary dressings with $\mathrm{CaOH}$ only showed a minor antibacterial effect on E. faecalis inside the dentinal tubules.

Further, it was found that irrigation with $1.3 \% \mathrm{NaOCl}$ was efficient in suppressing E. faecalis, too. Treatment for $20 \mathrm{~s}$ resulted in complete suppression of bacteria at the root canal walls, but failed to suppress the species inside the dentinal tubules completely.

When compared to the $\mathrm{NaCl}$-control, treatment with $1.3 \% \mathrm{NaOCl}$ caused significant bacterial suppression up to a penetration depth of $250 \mu \mathrm{m}$ (ISO 100, $p=0.001$ ). The correlation between ISO size and depth of bacterial penetration (distance of bacterial invasion into the dentinal tubules) is illustrated in Figure 5.

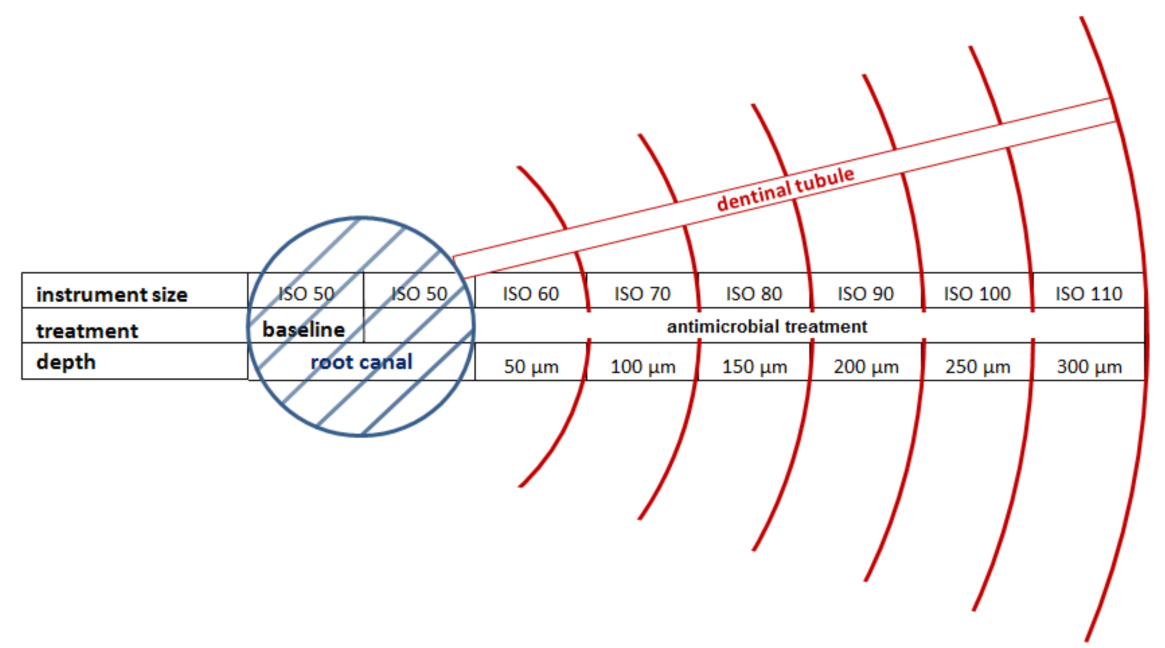

Figure 5. The image visualizes the correlation between ISO size of the applied endodontic file and depth of bacterial invasion into the dentinal tubules (image adopted and modified from Ossmann et al. [21]). Each manual instrumentation step with hand-held endodontic files resulted in an enlargement of the main root canal by $50 \mu \mathrm{m}$. Instrumentation up to file size ISO 110 resulted in abrasion of the root dentin by $300 \mu \mathrm{m}$.

\section{Discussion}

The aim of the present in vitro study was to investigate the antibacterial effect of $\mathrm{N}$-chlorotosylamidesodium salt (chloramine-T), $\mathrm{CaOH}$ and $\mathrm{NaOCl}$ on E. faecalis in infected dentinal tubules. Crystalline chloramine-T was delivered to the main root canals by either complete packing or by moistened and dip-coated paper points.

In the present study colonization of the dentinal tubules by $E$. faecalis was verified by scanning electron microscopy up to distances of at least $300 \mu \mathrm{m}$. Besides SEM evaluation, bacterial colonization was also confirmed by microbiological cultures analysis. Therefore our group developed and adapted an examination model that was published recently [21]. The applied method is based upon a stepwise enlargement of the main root canal with hand-held endodontic files and delivers detailed information upon the distance of bacterial penetration and bacterial load inside the dentinal tubules.

In a recent study, our group was also able to examine the colonization behavior of E. faecalis by using artificial $\mathrm{SiO} / \mathrm{SiO}_{2}$-micro-tubes. It was shown that bacterial colonization is strongly dependent upon the diameter and length of the tubes. Detailed examination revealed that within the same inoculation time tubes of wider diameter were colonized to a stronger extend compared to those of a smaller diameter. Further, a distance of penetration up to $500 \mu \mathrm{m}$ was verified for E. faecalis [30].

However, colonization of dentinal tubules by E. faecalis has been studied by many authors so far $[2,21,31,32]$. It was found, that the species, unlike other microbes, is able to invade the dentinal tubules also by itself [33]. Once entered, E. faecalis can persists inside the tubules by adhering to collagen type-I fibers [2]. Because the species is well adapted 
to the predominant environment inside the dentinal tubules, colonization and biofilm formation begins quickly [34-37]. In this context, the present in vitro study confirmed that E. faecalis was able to colonize the dentinal tubules up to distances of at least $300 \mu \mathrm{m}$ (ISO 110, Figures 3 and 4 ).

From all antiseptics tested, chloramine- $\mathrm{T}$ presented the strongest antibacterial activity. Dressings for $24 \mathrm{~h}$ caused total suppression of bacteria that have invaded the dentinal tubules.

In solid state, chloramine- $\mathrm{T}$ is of crystalline appearance and formed by a reaction of chlorine with nitrogenous compounds. In aqueous surrounding chloramine-T dissociates into sodium hypochloride (Figure 6A) and further into active hypochloric acid (Figure 6B).

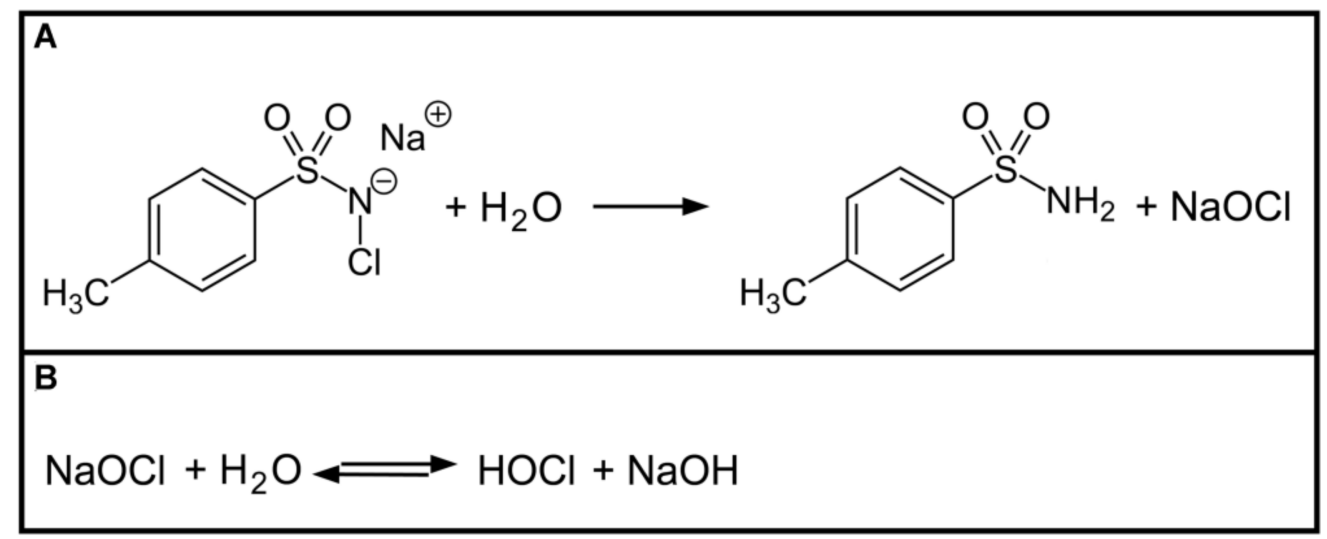

Figure 6. Dissociation of chloramine-T and $\mathrm{NaOCl}$. (A) In the presence of water chloramine-T dissociates into $\mathrm{NaOCl}$. (B) As in case of sodium hypochlorite, the active agent is hypochloric acid.

In contrast to $\mathrm{NaOCl}$ that is commonly used in chemo-mechanical root canal preparation, the release of reactive chlorine from chloramine-T occurs rather slowly which results in prolonged antibacterial activity $[24,38]$. Because of the dissociation kinetics, the overall antibacterial effect of chloramine- $\mathrm{T}$ is much stronger compared to irrigations with $\mathrm{NaOCl}$.

During the dissociation process, microorganisms such as E. faecalis are lethally damaged by oxidative reactions [39]. Investigations have shown that contact of microorganisms to chloramine-T results in distraction of the cell wall and an increase in permeability [28]

Within the limitations of this study, it was shown that chloramine-T delivered by paper points showed an insufficient antibacterial effect. Due to the lack of preliminary studies, investigations that evaluate the optimum concentration of chloramine-T, especially for paper point application are still needed.

If higher drug concentrations were applied, antibacterial efficiency would have probably increased. However, stronger concentrations will cause an increase in cytotoxicity, too. Because the dental roots are surrounded by different soft and hard tissues, drugs that diffuse out of the root canal system might cause severe irritations, leading to persistent signs of inflammation.

In clinical practice $\mathrm{NaOCl}$ is commonly applied during chemo-mechanical root canal preparation in concentrations normally ranging in between 0.5 and $5 \% . \mathrm{NaOCl}$ acts antimicrobial and also sows tissue dissolution abilities. When applied to root canals, immediate reactions with surrounding organic material will take place, leading to quick depletion. In clinical practice $\mathrm{NaOCl}$ solution is therefore commonly applied for irrigation purpose (short application time), only.

Guiteras et al. compared the activity of $\mathrm{NaOCl}$ and chloramine- $\mathrm{T}$ on organic substrates. It was found that in case of $\mathrm{NaOCl}$ available chlorine was detected for $1 \mathrm{~h}$, only. In contrary, chloramine-T showed available chlorine for more than $24 \mathrm{~h} \mathrm{[40].}$

As shown in Figure 6, salvation of chloramine-T needs to take place first. Afterwards dissociation to active $\mathrm{NaOCl}$ occurs. In comparison to irrigation with $\mathrm{NaOCl}$ fluid, chloramine-T is therefore antibacterial for a much longer period of time. 
Other than irrigation with $\mathrm{NaOCl}$ fluid, chloramine-T was applied in the present study by means of a temporary antiseptic root canal filling for $24 \mathrm{~h}$. Because chloramine-T shows a prolonged antibacterial effect, suppression of bacteria, especially inside dentinal tubules, is much more efficient compared to irrigations with $\mathrm{NaOCl}$.

In the present study, the effect of chloramine- $T$ was also compared to the antibacterial effect of a temporary dressing with calcium hydroxide. It was found that crystalline chloramine-T was most efficient in suppressing E. faecalis, while application of calcium hydroxide only resulted in minor bacterial suppression inside the dentinal tubules (Figure 4). The results are in line with findings of other authors that reported upon a reduced antimicrobial activity of calcium hydroxide on E. faecalis in infected dental root canals, too [13,41].

However, calcium hydroxide is still one of the most recommended temporary dressing agent applied [42]. Calcium hydroxide also presents some antimicrobial activity that is mainly based upon the dissociation of the compound into calcium and hydroxyl ions which cause distraction of lipopolysaccharides inside the bacterial cell wall $[43,44]$. The dissociation thereby is also influenced by the kind of calcium hydroxide formulation applied and was found to be strongest for compositions with polyethylene glycol [45]. However, overall, the antibacterial activity of calcium hydroxide on E. faecalis is often rather insufficient $[13,14,46]$.

In the present study the effect of irrigations with sodium hypochlorite solution on E. faecalis was also observed. So far, authors already confirmed the antibacterial activity of $\mathrm{NaOCl}$ on $E$. faecalis and showed that the effect is strongly dependent upon the applied concentration and irrigation time $[47,48]$. As shown in the present study, irrigation with $1.3 \% \mathrm{NaOCl}$ solution caused complete suppression of bacteria that colonized the walls of the main root canals directly, but failed complete suppression inside the dentinal tubules. The applied concentration was rather low. Application of a stronger solution might probably also cause an increase in antibacterial efficiency. Additionally, ultrasonic agitation and the use of pulsed lasers for activation are common strategies in order to increase the disinfection capability, but were not applied in the present study neither $[49,50]$.

The antibacterial effect of sodium hypochlorite, similar to calcium hydroxide, can thereby also be referred to its alkaline $\mathrm{pH}$ [51]. Contact of microorganisms to $\mathrm{NaOCl}$ causes peroxidation of lipids and leads to damage of cytoplasmic membranes. In addition, it was found that a reaction of $\mathrm{NaOCl}$ with surrounding organic material results in the formation of chloramines that themselves have a negative effect on the cells' metabolism [51,52].

Recently, the effect of chloramine-T on E. faecalis was also observed by Wang et al. It was ascertained that chloramine-T shows promising results [53]. In accordance, a former microscopic based analysis highlighted the potential of chloramine- $T$ as efficient disinfectant in the treatment of infected dental root canals, too [54].

The results of the present study demonstrated that from all disinfectants tested, crystalline chloramine-T showed the strongest antibacterial activity and was even capable in complete suppression of bacteria that have penetrated far into the dentinal tubules. In conclusion, it can be assumed that application of chloramine-T might even help to improve endodontic disinfection. As shown in a recent study, the maintenance of teeth by proper endodontic therapy should in the most cases be the first options in order to prevent insertion of cost intensive dental implants [55]. Further clinical investigations are necessary in order to proof the efficacy and safety of chloramine-T also in vivo.

\section{Conclusions}

The results of the present in vitro study proofed that from all antiseptics tested, chloramine- $\mathrm{T}$ showed the strongest antibacterial activity. Unlike treatment with $\mathrm{NaOCl}$ and $\mathrm{CaOH}$, application of crystalline chloramine-T was also efficient in eradicating bacteria that have penetrated far into the dentinal tubules. In the case of chloramine-T, a disinfection range of $300 \mu \mathrm{m}$ was estimated. In conclusion, chloramine-T shows promising characteristics and might be an auspicious alternative to antimicrobials commonly used in endodontic antiseptic therapy. 
Supplementary Materials: The following are available online at https://www.mdpi.com/article/10 .3390/ma14092427/s1, Figure S1: Chloramine-T CP, Figure S2: Chloramine-T PP, Figure S3: CaOH, Figure S4: NaOCl.

Author Contributions: Conceptualization, S.K., A.G., F.B. and S.T.-M.; methodology, S.K., S.T.-M., A.G., M.H., B.S. and F.B.; software, S.K., F.B. and S.T.-M.; validation, F.B., S.T.-M. and A.G.; formal analysis, F.B., A.G., S.K. and S.T.-M.; investigation, S.K., S.T.-M., M.H. and M.R.; resources, F.B., A.G., and S.K.; data curation, F.B., S.T.-M. and A.G.; writing-original draft preparation, S.K., F.B. and A.G.; writing-review and editing, S.K., A.G., F.B. and B.S.; visualization, A.G., F.B. and S.K.; supervision, B.S.; project administration, B.S. All authors have read and agreed to the published version of the manuscript.

Funding: This research received no external funding.

Institutional Review Board Statement: Not applicable.

Informed Consent Statement: Not applicable.

Data Availability Statement: Not applicable.

Acknowledgments: We acknowledge our families for their kind support.

Conflicts of Interest: The authors declare no conflict of interest.

\section{References}

1. Nair, P.N.; Henry, S.; Cano, V.; Vera, J. Microbial status of apical root canal system of human mandibular first molars with primary apical periodontitis after "one-visit" endodontic treatment. Oral Surg. Oral Med. Oral Pathol. Oral Radiol. Endod. 2005, 99, 231-252. [CrossRef] [PubMed]

2. Prada, I.; Micó-Muñoz, P.; Giner-Lluesma, T.; Micó-Martínez, P.; Collado-Castellano, N.; Manzano-Saiz, A. Influence of microbiology on endodontic failure. Literature review. Med Oral Patol Oral Cir. Bucal 2019, 24, e364-e372. [CrossRef] [PubMed]

3. Dioguardi, M.; Di Gioia, G.; Illuzzi, G.; Arena, C.; Caponio, V.C.A.; Caloro, G.A.; Zhurakivska, K.; Adipietro, I.; Troiano, G.; Lo Muzio, L. Inspection of the Microbiota in Endodontic Lesions. Dent. J. 2019, 7, 47. [CrossRef] [PubMed]

4. Zhang, C.; Du, J.; Peng, Z. Correlation between Enterococcus faecalis and Persistent Intraradicular Infection Compared with Primary Intraradicular Infection: A Systematic Review. J. Endod. 2015, 41, 1207-1213. [CrossRef]

5. Zargar, N.; Marashi, M.A.; Ashraf, H.; Hakopian, R.; Beigi, P. Identification of microorganisms in persistent/secondary endodontic infections with respect to clinical and radiographic findings: Bacterial culture and molecular detection. Iran J. Microbiol. 2019, 11, 120-128. [CrossRef]

6. Komiyama, E.Y.; Lepesqueur, L.S.; Yassuda, C.G.; Samaranayake, L.P.; Parahitiyawa, N.B.; Balducci, I.; Koga-Ito, C.Y. Enterococcus Species in the Oral Cavity: Prevalence, Virulence Factors and Antimicrobial Susceptibility. PLoS ONE 2016, 11, e0163001. [CrossRef]

7. Sedgley, C.M.; Nagel, A.C.; Shelburne, C.E.; Clewell, D.B.; Appelbe, O.; Molander, A. Quantitative real-time PCR detection of oral Enterococcus faecalis in humans. Arch. Oral Biol. 2005, 50, 575-583. [CrossRef]

8. Siqueira, J.F.J.; Antunes, H.S.; Rocas, I.N.; Rachid, C.T.; Alves, F.R. Microbiome in the Apical Root Canal System of Teeth with Post-Treatment Apical Periodontitis. PLoS ONE 2016, 11, e0162887. [CrossRef]

9. Du, T.; Wang, Z.; Shen, Y.; Ma, J.; Cao, Y.; Haapasalo, M. Effect of long-term exposure to endodontic disinfecting solutions on young and old Enterococcus faecalis biofilms in dentin canals. J. Endod. 2014, 40, 509-514. [CrossRef]

10. Haseeb, R.; Lau, M.; Sheah, M.; Montagner, F.; Quiram, G.; Palmer, K.; Stefan, M.C.; Rodrigues, D.C. Synthesis and Characterization of New Chlorhexidine-Containing Nanoparticles for Root Canal Disinfection. Materials 2016, 9, 452. [CrossRef]

11. Jose, J.; Krishnamma, S.; Peedikayil, F.; Aman, S.; Tomy, N.; Mariodan, J.P. Comparative Evaluation of Antimicrobial Activity of QMiX, 2.5\% Sodium Hypochlorite, 2\% Chlorhexidine, Guava Leaf Extract and Aloevera Extract Against Enterococcus faecalis and Candida albicans - An in-vitro Study. J. Clin. Diagn. Res. JCDR 2016, 10, Zc20. [CrossRef]

12. Eneide, C.; Castagnola, R.; Martini, C.; Grande, N.M.; Bugli, F.; Patini, R.; Cordaro, M.; Sanguinetti, M.; Olivi, G.; Isola, G.; et al. Antibiofilm Activity of Three Different Irrigation Techniques: An in Vitro Study. Antibiotcs 2019, 8, 112. [CrossRef]

13. Asnaashari, M.; Eghbal, M.J.; Sahba Yaghmayi, A.; Shokri, M.; Azari-Marhabi, S. Comparison of Antibacterial Effects of Photodynamic Therapy, Modified Triple Antibiotic Paste and Calcium Hydroxide on Root Canals Infected with Enterococcus faecalis: An In Vitro Study. J. Lasers Med. Sci. 2019, 10, S23-S29. [CrossRef]

14. Ran, S.; He, Z.; Liang, J. Survival of Enterococcus faecalis during alkaline stress: Changes in morphology, ultrastructure, physiochemical properties of the cell wall and specific gene transcripts. Arch. Oral Biol. 2013, 58, 1667-1676. [CrossRef]

15. George, M.; Ivancakova, R. Root canal microflora. Acta Med. 2007, 50, 7-15. [CrossRef]

16. Kim, R.J.; Kim, M.O.; Lee, K.S.; Lee, D.Y.; Shin, J.H. An in vitro evaluation of the antibacterial properties of three mineral trioxide aggregate (MTA) against five oral bacteria. Arch. Oral Biol. 2015, 60, 1497-1502. [CrossRef] 
17. Rocas, I.N.; Siqueira, J.F.J. Detection of antibiotic resistance genes in samples from acute and chronic endodontic infections and after treatment. Arch. Oral Biol. 2013, 58, 1123-1128. [CrossRef]

18. Li, Y.; Wang, Y.; Chen, X.; Jiang, W.; Jiang, X.; Zeng, Y.; Li, X.; Feng, Z.; Luo, J.; Zhang, L. Antimicrobial peptide GH12 as root canal irrigant inhibits biofilm and virulence of Enterococcus faecalis. Int. Endod. J. 2020, 53, 948-961. [CrossRef]

19. Ong, T.H.; Chitra, E.; Ramamurthy, S.; Siddalingam, R.P.; Yuen, K.H.; Ambu, S.P.; Davamani, F. Chitosan-propolis nanoparticle formulation demonstrates anti-bacterial activity against Enterococcus faecalis biofilms. PLoS ONE 2017, 12, e0174888.

20. Walsh, L.J. Novel Approaches to Detect and Treat Biofilms within the Root Canals of Teeth: A Review. Antibiotcs 2020, 9 , 129. [CrossRef]

21. Ossmann, A.; Kranz, S.; Andre, G.; Volpel, A.; Albrecht, V.; Fahr, A.; Sigusch, B.W. Photodynamic killing of Enterococcus faecalis in dentinal tubules using mTHPC incorporated in liposomes and invasomes. Clin. Oral Investig. 2015, 19, 373-384. [CrossRef] [PubMed]

22. Zilm, P.S.; Butnejski, V.; Rossi-Fedele, G.; Kidd, S.P.; Edwards, S.; Vasilev, K. D-amino acids reduce Enterococcus faecalis biofilms in vitro and in the presence of antimicrobials used for root canal treatment. PLoS ONE 2017, 12, e0170670. [CrossRef] [PubMed]

23. Betancourt, P.; Sierra, J.M.; Camps-Font, O.; Arnabat-Domínguez, J.; Viñas, M. Er,Cr:YSGG Laser-Activation Enhances Antimicrobial and Antibiofilm Action of Low Concentrations of Sodium Hypochlorite in Root Canals. Antibiotcs 2019, 8, 232. [CrossRef] [PubMed]

24. Kloth, L.C.; Berman, J.E.; Laatsch, L.J.; Kirchner, P.A. Bactericidal and cytotoxic effects of chloramine-T on wound pathogens and human fibroblasts in vitro. Adv. Ski. Wound Care 2007, 20, 331-345. [CrossRef]

25. Gowda, N.M.; Trieff, N.M.; Stanton, G.J. Inactivation of poliovirus by chloramine-T. Appl. Environ. Microbiol. 1981, 42, 469-476. [CrossRef]

26. Sattar, S.A.; Springthorpe, V.S.; Karim, Y.; Loro, P. Chemical disinfection of non-porous inanimate surfaces experimentally contaminated with four human pathogenic viruses. Epidemiol. Infect. 1989, 102, 493-505. [CrossRef]

27. Tirapelli, C.; Landi, F.; Ribas, J.P.; Panzeri, H.; Lara, E.H. Evaluating an experimental dentifrice containing chloramine-T: A preliminary study. Oral Health Prev. Dent. 2010, 8, 375-381.

28. Ferreira, G.L.S.; Rosalen, P.L.; Peixoto, L.R.; Perez, A.; Carlo, F.G.C.; Castellano, L.R.C.; Lima, J.M.; Freires, I.A.; Lima, E.O.; Castro, R.D. Antibiofilm Activity and Mechanism of Action of the Disinfectant Chloramine T on Candida spp., and Its Toxicity against Human Cells. Molecules 2017, 22, 1527. [CrossRef]

29. Kneist, S.; Nietzsche, S.; Küpper, H.; Raser, G.; Willershausen, B.; Callaway, A. Penetration of Streptococcus sobrinus and Streptococcus sanguinis into dental enamel. Anaerobe 2015, 35, 54-59. [CrossRef]

30. Sigusch, B.W.; Kranz, S.; Klein, S.; Volpel, A.; Harazim, S.; Sanchez, S.; Watts, D.C.; Jandt, K.D.; Schmidt, O.G.; Guellmar, A. Colonization of Enterococcus faecalis in a new $\mathrm{SiO} / \mathrm{SiO}(2)$-microtube in vitro model system as a function of tubule diameter. Dent. Mater. Off. Publ. Acad. Dent. Mater. 2014, 30, 661-668. [CrossRef]

31. De Lucena, J.M.; Decker, E.M.; Walter, C.; Boeira, L.S.; Lost, C.; Weiger, R. Antimicrobial effectiveness of intracanal medicaments on Enterococcus faecalis: Chlorhexidine versus octenidine. Int. Endod. J. 2013, 46, 53-61. [CrossRef]

32. Schafer, E.; Bossmann, K. Antimicrobial efficacy of chlorhexidine and two calcium hydroxide formulations against Enterococcus faecalis. J. Endod. 2005, 31, 53-56. [CrossRef]

33. Vatkar, N.A.; Hegde, V.; Sathe, S. Vitality of Enterococcus faecalis inside dentinal tubules after five root canal disinfection methods. J. Conserv. Dent. 2016, 19, 445-449. [CrossRef]

34. De Paula, V.A.; de Carvalho Ferreira, D.; Cavalcante, F.S.; do Carmo, F.L.; Rosado, A.S.; Primo, L.G.; dos Santos, K.R. Clinical signs and bacterial communities of deciduous necrotic root canals detected by PCR-DGGE analysis: Research association. Arch. Oral Biol. 2014, 59, 848-854. [CrossRef]

35. Gomes, B.P.; Souza, S.F.; Ferraz, C.C.; Teixeira, F.B.; Zaia, A.A.; Valdrighi, L.; Souza-Filho, F.J. Effectiveness of $2 \%$ chlorhexidine gel and calcium hydroxide against Enterococcus faecalis in bovine root dentine in vitro. Int. Endod. J. 2003, 36, 267-275. [CrossRef]

36. Love, R.M. Enterococcus faecalis-a mechanism for its role in endodontic failure. Int. Endod. J. 2001, 34, 399-405. [CrossRef]

37. Love, R.M. Bacterial adhesins-their role in tubule invasion and endodontic disease. Aust. Endod. J. 2002, 28, 25-28. [CrossRef]

38. Milroy, T.H. The Action of Hypochlorites and Allied Substances on Proteins, and their Behaviour on Injection. Biochem. J. 1916, 10, 453-465. [CrossRef]

39. Stralfors, A.; Thilander, H.; Bergenholtz, A. Simultaneous inhibition of caries and periodontal disease in hamsterby disinfection, tooth-brushing or phosphate addition. Arch. Oral Biol. 1967, 12, 1367-1373. [CrossRef]

40. Guiteras, A.F.; Schmelkes, F.C. The comparative action of sodium hypochlorite, chloramine-T, and azochloramid on organic substrates. J. Biol. Chem. 1934, 107, 235-239. [CrossRef]

41. Mozayeni, M.A.; Haeri, A.; Dianat, O.; Jafari, A.R. Antimicrobial effects of four intracanal medicaments on enterococcus faecalis: An in vitro study. Iran. Endod. J. 2014, 9, 195-198.

42. Kawashima, N.; Wadachi, R.; Suda, H.; Yeng, T.; Parashos, P. Root canal medicaments. Int. Dent. J. 2009, $59,5-11$.

43. Siqueira, J.F.J.; Lopes, H.P. Mechanisms of antimicrobial activity of calcium hydroxide: A critical review. Int. Endod. J. 1999, 32, 361-366. [CrossRef]

44. Athanassiadis, B.; Walsh, L.J. Aspects of Solvent Chemistry for Calcium Hydroxide Medicaments. Materials 2017, 10, 1219. [CrossRef] 
45. Teoh, Y.Y.; Athanassiadis, B.; Walsh, L.J. Comparison of Commercial Calcium Hydroxide Pastes for Prolonged Antibacterial Effect using a Colourimetric Assessment. Materials 2018, 11, 348. [CrossRef]

46. Evans, M.; Davies, J.K.; Sundqvist, G.; Figdor, D. Mechanisms involved in the resistance of Enterococcus faecalis to calcium hydroxide. Int. Endod. J. 2002, 35, 221-228. [CrossRef]

47. Borzini, L.; Condo, R.; De Dominicis, P.; Casaglia, A.; Cerroni, L. Root Canal Irrigation: Chemical Agents and Plant Extracts Against Enterococcus faecalis. Open Dent. J. 2016, 10, 692-703. [CrossRef]

48. Sahebi, S.; Khosravifar, N.; Sedighshamsi, M.; Motamedifar, M. Comparison of the antibacterial effect of sodium hypochlorite and aloe vera solutions as root canal irrigants in human extracted teeth contaminated with enterococcus faecalis. J. Dent. 2014, 15, 39-43.

49. Walsh, L.J.; George, R. Activation of Alkaline Irrigation Fluids in Endodontics. Materials 2017, 10, 1214. [CrossRef]

50. Choi, H.W.; Park, S.Y.; Kang, M.K.; Shon, W.J. Comparative Analysis of Biofilm Removal Efficacy by Multisonic Ultracleaning System and Passive Ultrasonic Activation. Materials 2019, 12, 3492. [CrossRef]

51. Estrela, C.; Estrela, C.R.; Barbin, E.L.; Spano, J.C.; Marchesan, M.A.; Pecora, J.D. Mechanism of action of sodium hypochlorite. Braz. Dent. J. 2002, 13, 113-117. [CrossRef] [PubMed]

52. Buttler, T.K.; Crawford, J.J. The detoxifying effect of varying concentrations of sodium hypochlorite on endotoxins. J. Endod. 1982, 8, 59-66. [CrossRef]

53. Wang, D.M.; Gao, X.J.; Shen, S. Comparison of antimicrobial efficacy of four endodontic irrigants using an in vitro model infected by Enterococcus faecalis. Chin. J. Stomatol. 2007, 42, 223-224.

54. Qi, P. An experimental study on cleaning efficacy of several root canal irrigants. Chin. J. Stomatol. 1991, 26, $205-207$.

55. Esposito, M.; Trullenque-Eriksson, A.; Tallarico, M. Endodontic retreatment versus dental implants of teeth with an uncertain endodontic prognosis: 3-year results from a randomised controlled trial. Eur. J. Oral Implantol. 2018, 11, $423-438$. 